\title{
Defining and improving postoperative care
}

\author{
Thomas A. D'Amico, MD
}

See related articles on pages 2261-7 and 2269-78.

Strategies to improve outcomes after resection for lung cancer and esophageal cancer have focused on preoperative evaluation, multidisciplinary evaluation and management, operative technique, and immediate perioperative management. ${ }^{1,2}$ It has become increasingly clear, however, that longer-term postoperative management also has a significant influence on operative results. ${ }^{3-5}$ Bryant and colleagues ${ }^{6}$ have previously reported that the interval mortality between 30 days and 90 days is approximately equal to the 30-day mortality after pulmonary resection, challenging the definition of "operative mortality" and emphasizing the importance of continued postoperative care throughout at least the first 3 months after surgery.

In this issue of the Journal, Pezzi and colleagues ${ }^{3}$ demonstrate an even larger difference between 30-day and 90-day mortality. This study analyzed major lung resection from 2007 to 2011 in the National Cancer Database. Among 124,418 patients who underwent major lung resection, the 30 -day morality was $2.8 \%$ and the 90 -day morality was $5.4 \%$, nearly twice as high. Important factors that predicted mortality include age, stage, extent of resection, and other medical comorbidities. Although none of these factors can be altered with the intent of improving mortality, understanding the risk factors involved would allow the development of risk models to better predict complications and focus resources on the patients who need them the most. In addition, with this information it is possible for surgeons and hospitals to benchmark results, which may be most important for hospitals with low operative volume. Pezzi and colleagues ${ }^{3}$ focus too much attention on hospital volume, whereas systematic improvements in patient monitoring and care could be just as successful in low-volume hospitals as in high-volume hospitals.

It thus appears that the identification of risk factors that predict mortality between 30 and 90 postoperative days

\footnotetext{
From the Section of General Thoracic Surgery, Department of Surgery, Duke University Medical Center, Durham, NC.

Disclosures: Author has nothing to disclose with regard to commercial support.

Received for publication Sept 28, 2014; accepted for publication Sept 29, 2014.

Address for reprints: Thomas A. D'Amico, MD, Section of General Thoracic Surgery Program Director, Thoracic Surgery, Duke University Medical Center, DUMC Box 3496, Duke South, White Zone, Room 3589, Durham, NC 27710 (E-mail: thomas. damico@duke.edu).

J Thorac Cardiovasc Surg 2014;148:1792-3

$0022-5223 / \$ 36.00$

Copyright (c) 2014 by The American Association for Thoracic Surgery

http://dx.doi.org/10.1016/j.jtcvs.2014.09.095
}

would potentially have a larger impact on overall operative outcomes. Also in this issue of the Journal, $\mathrm{Hu}$ and coworkers ${ }^{4}$ demonstrate that readmission after lung cancer resection is associated with a 6-fold increase in mortality, further illustrating the importance of postoperative care at least through the first 3 months after surgery. In this study, $\mathrm{Hu}$ and coworkers ${ }^{4}$ analyze the Surveillance, Epidemiology and End Results-Medicare registry from 2006 to 2011. The 30-day readmission rate was $12.8 \%$, and among readmitted patients the 90-day mortality was $14.4 \%, 6$ times the baseline mortality of $2.5 \%$. Of note, the rate of readmission was significantly associated with age and extent of procedure, among other factors, allowing investigators to develop a risk model to predict readmission with the intent of focusing attention and resources on the patients who are most likely to readmitted, as articulated in the article. Because the study is based on a Medicare administrative database, it excludes patients younger than 65 years, and various clinical factors that affect decision making regarding discharge and readmission are not included. Most importantly, the study is limited in its ability to identify which readmissions are preventable and which patients, once readmitted, can be treated successfully, although it is thought that the majority of surgical readmissions are not preventable. 7,8

Once patients with lung cancer survive through 90 days, the management focuses on cancer-specific surveillance. ${ }^{1}$ There is significant controversy regarding the frequency of follow-up, whether surveillance should include other modalities other than interval history and physical examination, and the use of radiographic surveillance. In this issue, Crabtree and colleagues ${ }^{5}$ report their study of the use of computed tomography (CT) versus chest radiography $(\mathrm{CXR})$ in a single-institution series of 554 patients who underwent resection for stage I lung cancer from 2001 through 2013. In this series, there was no difference in 5-year survival or detection of successive malignancies whether radiographic surveillance included CXR or CT. Although the study may inform clinicians regarding the utility of CT scanning after resection for stage I lung cancer, one should exercise caution before implementing broad changes in practice. The study did not control for how it was decided to use CT or CXR, and the authors cannot exclude selection bias among the subsets of stage I disease that do not have equivalent survival. Also, the study does not address other potential benefits of CT surveillance in a patient population with a significant incidence of coronary artery and vascular disease. ${ }^{9}$ Finally, as CT scans improve from generation to generation, the differences in cost and exposure are decreasing, narrowing 
any potential benefits of CXR relative to CT. It does seem reasonable to use only CXR for selected patients in whom oncologic reintervention is less likely to monitor for issues that would require palliative intervention, such as pneumothorax, pleural effusion, and pericardial effusion.

\section{SUMMARY}

Although much is known regarding the importance of postoperative care, the surveillance of patients after 30 days from the surgical procedure can be improved. It must be recognized that mortality between 30 and 90 days exceeds what is commonly considered "operative mortality" - death within 30 days of surgery. Significant effort should be dedicated to the design of predictive models to prevent readmission. More importantly, surgeons must develop better models to manage the complications that arise after readmission to prevent mortality in readmitted patients. Finally, current guidelines for oncologic surveillance are an area of controversy, and future studies are needed for better direction of resources.

\section{References}

1. Ettinger DS, Akerly W, Borghaei H, Chang A, Cheney RT, Chirieac LR, et al; National Comprehensive Cancer Network (NCCN). Non-small cell lung cancer. $J$ Natl Compr Canc Netw. 2012;10:1236-71.

2. Ajani JA, Barthel JS, Bentrem DJ, D'Amico TA, Das P, Denlinger CS, et al; National Comprehensive Cancer Network. Esophageal and esophagogastric junction cancers. J Natl Compr Canc Netw. 2011;9:830-87.

3. Pezzi CM, Mallin K, Mendez AS, Greer Gay E, Putnam JB Jr. Ninety-day mortality after resection for lung cancer is nearly double 30-day mortality. J Thorac Cardiovasc Surg. 2014;148:2269-78.

4. Hu Y, McMurry TL, Isbell JM, Stukenborg GJ, Kozower BD. Readmission after lung cancer resection is associated with a 6-fold increase in 90-day postoperative mortality. J Thorac Cardiovasc Surg. 2014;148:2261-7.

5. Crabtree TD, Puri V, Chen SB, Gierada DS, Bell JM, Broderick S, et al. Does the method of radiologic surveillance affect survival after resection of stage I nonsmall cell lung cancer? J Thorac Cardiovasc Surg. August 8, 2014 [Epub ahead of print].

6. Bryant AS, Rudemiller K, Cerfolio RJ. The 30- versus 90-day operative mortality after pulmonary resection. Ann Thorac Surg. 2010;89:1717-22; discussion 1722-3.

7. Dawes AJ, Sacks GD, Russell MM, Lin AY, Maggard-Gibbons M, Winograd D, et al. Preventable readmissions to surgical services: lessons learned and targets for improvement. J Am Coll Surg. 2014;219:382-9.

8. Wiseman JT, Guzman AM, Fernandez-Taylor S, Engelbert TL, Saunders RS, Kent KC. General and vascular surgery readmissions: a systematic review. J Am Coll Surg. 2014;219:552-69.e2.

9. Mulshine JL, D'Amico TA. Issues with implementing a high-quality lung cancer screening program. CA Cancer J Clin. 2014;64:351-63. 